\title{
Comparative study of video-assisted thoracoscopic surgery versus open thymectomy for thymoma and myasthenia gravis
}

\author{
Ezel Erşen ${ }^{1}$, Burcu Kılıç ${ }^{1}$, Hasan Volkan Kara ${ }^{1}$, Mehlika İşcan $^{1}$, İsmail Sarbay ${ }^{1}$, Ahmet Demirkaya ${ }^{2}$, Selim Bakan $^{3}$, \\ Melih Tütüncü ${ }^{4}$, Akif Turna ${ }^{1}$, Kamil Kaynak ${ }^{1}$ \\ ${ }^{1}$ Department of Thoracic Surgery, Cerrahpasa Faculty of Medicine, Istanbul University, Istanbul, Turkey \\ ${ }^{2}$ Department of Thoracic Surgery, School of Medicine, Istanbul Acıbadem University, Istanbul, Turkey \\ ${ }^{3}$ Department of Radiology, Cerrahpasa Faculty of Medicine, Istanbul University, Istanbul, Turkey \\ ${ }^{4}$ Department of Neurology, Cerrahpasa Faculty of Medicine, Istanbul University, Istanbul, Turkey
}

Videosurgery Miniinv 2018; 13 (3): 376-382 DOI: https://doi.org/10.5114/wiitm.2018.75835

\begin{abstract}
Introduction: Thymectomy is the preferred standard treatment in younger non-thymoma patients with myasthenia gravis as well as in patients with early stage thymoma. Total thymectomy by median sternotomy has been the surgical approach since resection of the thymus with video-assisted thoracoscopic surgery (VATS).

Aim: To compare the clinical outcomes of VATS thymectomy with conventional open thymectomy for neoplastic and non-neoplastic thymic diseases.

Material and methods: Forty patients underwent thymectomy between October 2012 and January 2016. Fifteen patients were male and 25 patients were female. The mean age was $40.3 \pm 17.7$ years. Seventeen (55\%) patients underwent VATS thymectomy and 23 (45\%) patients underwent an open procedure. We retrospectively reviewed the data of the patients and compared these two techniques.

Results: The mean tumor size was $5.17 \pm 3.2 \mathrm{~cm}$ in the thymoma group (VATS $2.5 \pm 2.4 \mathrm{~cm}$ vs. open access $4.7 \pm 3.7 \mathrm{~cm}$ ). None of the patients experienced a myasthenic crisis. Conversion to thoracotomy was required in 1 patient in the VATS group due to bleeding from the right internal mammary artery; therefore, the conversion rate was $2.5 \%$ among all the patients. No mortality occurred in either group. No significant difference was found in the perioperative blood loss, operative time or pain visual analogue scale scores. On the other hand, regarding postoperative drainage, duration of chest tube drainage and length of hospital stay, VATS thymectomy yielded better results and the differences were significant. Conclusions: Video-assisted thoracoscopic surgery thymectomy can be performed for both neoplastic and non-neoplastic thymic diseases with minimal morbidity and mortality.
\end{abstract}

Key words: video-assisted thoracoscopic surgery, thymus, myasthenia graves, thymoma, open surgery.

\section{Introduction}

Thymectomy is the preferred standard treatment in younger non-thymoma patients with myasthenia gravis as well as in patients with early stage thymoma [1]. Total thymectomy by median sternotomy has been the surgical approach since resection of the thymus with video-assisted thoracoscopic surgery (VATS) was first reported in the late 1990s [1-3].

The most important long-term prognostic factor in malignant thymic tumors is complete surgical resection [4-6]. According to a recent meta-analysis, VATS thymectomy was found to be as safe and fea-

\section{Address for correspondence}

Ezel Erşen, Department of Thoracic Surgery, Cerrahpasa Faculty of Medicine, Istanbul University, 34098 Istanbul, Turkey,

phone: +90 5057311567, e-mail: drezelersen@gmail.com 
sible as open thymectomy regarding oncologic outcomes and postoperative complication rates [7].

Myasthenia gravis (MG) is an auto-immune disease associated with abnormal antibodies binding to the acetylcholine receptors at the neuromuscular junction of the skeletal muscle, which causes destruction and modification of the neuromuscular junction. Patients usually present with weakness of the skeletal muscle, respiratory muscles, ocular muscles and bulbar muscles [8-10].

The prognosis of MG patients largely depends on the complete removal of the thymus tissue, and incomplete resection may mean higher recurrence rates. Video-assisted thoracoscopic surgery thymectomy in MG patients not only provides the chance to perform complete thymic resection, but also brings additional benefits such as less pain, smaller incisions, shorter length of hospital stay, and lower incidence of postoperative myasthenia crisis as well [11].

In our institute, thoracoscopic thymectomy has been performed since October 2012. In this study, we aimed to compare the clinical and surgical outcomes between VATS thymectomy and open thymectomy from October 2012 to January 2016 retrospectively. Our objective was to determine whether minimally invasive thymectomy was as safe and effective as open surgery.

\section{Aim}

The aim of this study is to compare the clinical outcomes of video-assisted thoracoscopic thymectomy with conventional open thymectomy for neoplastic and non-neoplastic thymic diseases.

\section{Material and methods}

In our institute, 40 patients underwent thoracoscopic and open thymectomy between October 2012 and January 2016. Fifteen patients were male and 25 patients were female aged between 9 and 75 years with the mean age $40.3 \pm 17.7$ years $(34.7 \pm 15.1$ in male patients and $43.6 \pm 18.6$ in female patients) (Table I). Seventeen (55\%) patients underwent VATS thymectomy and 23 (45\%) patients underwent an open procedure (partial sternotomy in 5 patients and sternotomy in 18 patients). Seventeen patients had comorbidities (42.5\%). In all of the thoracoscopic cases, we preferred the right-sided approach. Video-assisted thoracoscopic surgery thymectomies were carried out using three thoracic ports. Open thymectomy (sternotomy, partial sternotomy) was used for cases of thymomas larger than $>6 \mathrm{~cm}$. In one case, VATS was converted into a thoracotomy. The reason for the conversion was bleeding from the right mammary artery.

Thymic morphology revealed thymomas in 21 (52.5\%) patients and thymic hyperplasia in 8 (20\%) patients. Thymolipoma was found in $2(5 \%)$ patients, thymic cyst in 1 patient, thymus involution in 2 patients, thymic carcinoma in 3 patients, and neuroendocrine tumor in 1 patient. In 19 (47.5\%) cases, thymic pathology was associated with MG. A combination of MG and thymoma (thymoma-associated $M G$ ) was revealed in 7 patients ( $17.5 \%$ of all patients

Table I. Demographics and clinical characteristics

\begin{tabular}{|c|c|}
\hline Variable & Value \\
\hline Age, median \pm SD [years] & $40.3 \pm 17.7$ (range: $9-75)$ \\
\hline \multicolumn{2}{|l|}{ Gender, $n(\%)$ : } \\
\hline Male & $15(37.5)$ \\
\hline Female & $25(62.5)$ \\
\hline \multicolumn{2}{|l|}{ Type of surgery, $n(\%)$ : } \\
\hline VATS & $17(55)$ \\
\hline Open & $23(45)$ \\
\hline \multicolumn{2}{|l|}{ Thymic pathology, $n$ (\%): } \\
\hline Thymoma & $21(52.5)$ \\
\hline Hyperplasia & $8(20)$ \\
\hline Thymolipoma & $2(5)$ \\
\hline Thymic cyst & $1(2.5)$ \\
\hline Thymus involution & $2(5)$ \\
\hline Thymic carcinoma & $3(7.5)$ \\
\hline Neuroendocrine tumor & $1(2.5)$ \\
\hline Pre-op diagnosis of MG & $\begin{array}{c}19 \text { (47.5) (7 patients (17.5\%) } \\
\text { MG + thymoma) }\end{array}$ \\
\hline \multicolumn{2}{|l|}{ Comorbidity, $n(\%)$ : } \\
\hline Diabetes mellitus & $2(15)$ \\
\hline Hypertension & $5(32)$ \\
\hline Coronary heart disease & $3(23)$ \\
\hline COPD & $1(11)$ \\
\hline Renal dysfunction & $1(8)$ \\
\hline Arrhythmia & $2(6)$ \\
\hline Asthma & $2(4)$ \\
\hline
\end{tabular}


or $36.8 \%$ of all MG patients). The demographic data of the patients are presented in Table I. Histologic diagnoses were made according to the classification of thymomas by Masaoka et al. [5], Müller-Hermelink [12] and the World Health Organization (WHO) classification [13].

In patients with $M G$, the preoperative severity of the disease was classified according to the Osserman and Jenkins classification [14].

We retrospectively reviewed the data of the patients and compared preoperative and perioperative parameters (e.g. comorbidities, intravenous immunoglobulin (IVIG) treatment, operative time, blood loss, pleural drainage duration) and postoperative parameters (e.g. complications, postoperative myasthenia crisis, length of hospital stay) during the follow-up period.

\section{Surgical techniques}

\section{Video-assisted thoracoscopic surgery thymectomy}

The procedure is performed under general anesthesia with double-lumen intubation. The patient is placed in the semi-supine position with a 30-degree retroversion (Photo 1). The ipsilateral arm is placed over the head of the patient in a holder. In our series, a right-sided approach was performed in all patients. A camera port was placed at the eighth intercostal space midaxillary line, while two working ports were placed at the fourth intercostal space at

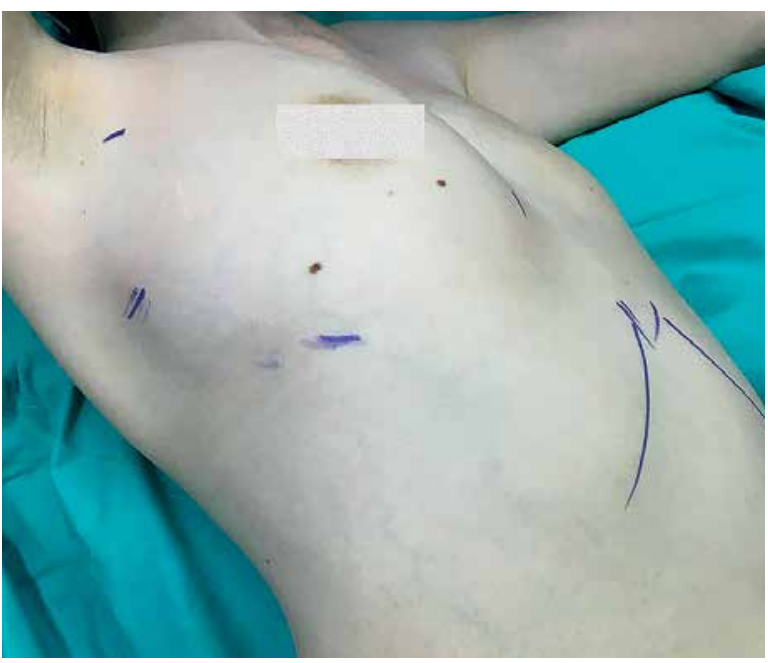

Photo 1. The patient is placed in the semi-supine position with 30-degree retroversion and the ipsilateral arm is placed over the head of the patient in a holder for thoracoscopic thymectomy the anterior axillary line and sixth intercostal space at the posterior axillary line. We started with dissection of the prepericardial fat above the right phrenic nerve. The whole thymic tissue and all of the anterior mediastinal fat were also dissected away approximately $1-1.5 \mathrm{~cm}$ anterior to the left phrenic nerve. Arterial supplies and venous drainage were ligated with hemoclips. Bilateral superior horns were dissected with blunt dissection. Thymus tissue and the prepericardial fat pad on the left side were removed extensively up to the left pleural margin. A right chest drain was placed in the right pleural space extending to the left pleura.

\section{Open thymectomy}

Under general anesthesia with single lumen intubation, the patient was placed in a supine position. The sternum was incised with an electric motor saw. Bilateral pleural spaces were opened, while an en bloc resection of the anterior mediastinal fat tissue together with the thymus was performed (Photo 2).



Photo 2. In open thymectomy, bilateral pleural spaces were opened and an en bloc resection of the anterior mediastinal fat tissue together with the thymus was performed 
The adipose tissues around the upper poles of the thymus, around both brachiocephalic veins, and on the pericardium were resected precisely. The extent of resection was up to the diaphragm caudally, the thyroid gland cranially, and the phrenic nerves laterally. One or two drainage tubes needed to be placed.

\section{Statistical analysis}

Statistical analysis was performed using Pearson's $\chi^{2}$ test for bivariate analysis. All statistical analyses were performed using IBM SPSS Statistics, version 20.0 (IBM Corp., Armonk, N.Y.). Values of $p<0.05$ were considered statistically significant.

\section{Results}

The mean age was $40.3 \pm 17.7$ years $(34.7 \pm 15.1$ in male patients and $43.6 \pm 18.6$ in female patients). Electromyography was positive in 17 (42.5\%) patients, and the acetylcholine receptor antibody test was positive in 13 (32.5\%) patients. Out of all the patients, 7 (17.5\%) were Osserman 1, 11 (27.5\%) were Osserman 2B and 1 (2.5\%) was Osserman 3. Seventeen patients were treated with pyridostigmine bromide with an average dosage of 250.58 $\pm 116.6 \mathrm{mg} /$ day. Twelve (30\%) patients also received corticosteroid medication with an average dosage of $11.7 \pm 20.7 \mathrm{mg} /$ day, while 8 (20\%) patients received intravenous immunoglobulin treatment prior to the surgery. The mean tumor size was $5.17 \pm 3.2 \mathrm{~cm}$ in the thymoma group (VATS $2.5 \pm 2.4 \mathrm{~cm}$ vs. open access $4.7 \pm 3.7 \mathrm{~cm}$ ).

All thymoma patients were classified according to the Masaoka, Müller-Hermelink and WHO classification systems (Table II). None of the patients experienced a myasthenic crisis. Conversion to thoracotomy was required in 1 patient in the VATS group due to bleeding from the right internal mammary artery; therefore, the conversion rate was $2.5 \%$ among all the patients, while the figure was $5.8 \%$ for VATS thymectomy. No mortality occurred in either group. The average duration of the operation was 130.65 \pm 24.6 min (range: $90-180 \mathrm{~min}$ ) for open thymectomy and $135 \pm 43.3 \mathrm{~min}$ (range: $90-210 \mathrm{~min}$ ) for VATS thymectomy $(p=0.344)$. Perioperative blood loss in VATS and open thymectomy were $117.6 \pm 233.3 \mathrm{ml}$ and $117.39 \pm 109.34 \mathrm{ml}$ respectively $(p=0.498)$. The difference in these two parameters was not statistically significant. On the other hand, regarding postoperative drainage, duration of chest tube drainage and length of hospital stay, VATS thymectomy yielded better results. Postoperative drainage was lower in the VATS group compared with the open access group $(191.17 \pm 204 \mathrm{ml} v \mathrm{~s} .440 .9 \pm 336.5 \mathrm{ml})$, and the difference was statistically significant $(p=0.005)$. Likewise, duration of chest tube drainage and length of hospital stay were shorter in the VATS group than the open thymectomy group, and the difference was statistically significant ( $p=0.039$ and $p=0.018)$. The average pain level using the visual analog pain score (VAS) was 4.3 for the VATS group and 3.5 for the open access group, and the difference was not significant $(p=0.118)$. The operative parameters are summarized in Table III.

Table II. Thymus pathology and classification

\begin{tabular}{|c|c|}
\hline Characteristic & $N(\%)$ \\
\hline \multicolumn{2}{|c|}{ WHO histologic type thymoma: } \\
\hline$A$ & $3(7.5)$ \\
\hline$A B$ & $1(2.5)$ \\
\hline B1 & $5(12.5)$ \\
\hline B2 & $8(20)$ \\
\hline B3 & $1(2.5)$ \\
\hline C & $3(7.5)$ \\
\hline \multicolumn{2}{|c|}{ Muller-Hermelink classification: } \\
\hline Medullary thymoma & $3(7.5)$ \\
\hline Mixed thymoma & $1(2.5)$ \\
\hline Cortical thymoma & $11(27.5)$ \\
\hline Thymic carcinoma & $3(7.5)$ \\
\hline \multicolumn{2}{|l|}{ Masaoka staging: } \\
\hline I & $8(20)$ \\
\hline$\| \mathrm{A}$ & $5(12.5)$ \\
\hline$\| B$ & $3(7.5)$ \\
\hline III & $2(5)$ \\
\hline IVA & $1(2.5)$ \\
\hline IVB & $1(2.5)$ \\
\hline \multicolumn{2}{|l|}{ Osserman classification: } \\
\hline 1 & $7(17.5)$ \\
\hline $2 \mathrm{~B}$ & $11(27.5)$ \\
\hline 3 & $1(2.5)$ \\
\hline
\end{tabular}

WHO - World Health Organization, MG - myasthenia gravis. 
Table III. Intra- and post-operative parameters

\begin{tabular}{|lccc|}
\hline Parameters & VATS & Open & $P$-value \\
\hline Operation time, mean \pm SD [min] & $135 \pm 43.3$ & $130.65 \pm 24.6$ & 0.344 \\
\hline Perioperative blood loss, mean \pm SD [ml] & $117.6 \pm 233.3$ & $117.3 \pm 109.3$ & 0.498 \\
\hline Chest tube duration, mean \pm SD [days] & $2.11 \pm 1.05$ & $2.68 \pm 0.89$ & 0.039 \\
\hline Postoperative drainage, mean \pm SD [ml] & $191.17 \pm 204$ & $440.9 \pm 336.5$ & 0.005 \\
\hline Hospital stay, mean \pm SD [days] & $3.2 \pm 1.2$ & $4.6 \pm 2.4$ & 0.018 \\
\hline Post-op VAS score & 4.3 & 3.5 & 0.118 \\
\hline
\end{tabular}

VATS - video-assisted thoracoscopic surgery, SD - standard deviation, VAS - visual analog pain score.

Fourteen patients required intensive care unit follow-up (range: $1-4$ days) and only 1 (2.5\%) patient required $12 \mathrm{~h}$ of mechanical ventilation postoperatively. Three (7.5\%) patients developed complications (1 minimal pneumothorax, 1 subcutaneous emphysema and 1 pneumonia). Adjuvant therapy was required in 8 (20\%) patients. Length of follow-up was $33.3 \pm 26.3$ months, while disease-free survival was $31.3 \pm 26.2$ months in all patients.

\section{Discussion}

With the advantages of minimal invasiveness and rapid recovery, VATS thymectomy has been gaining popularity in recent years in the treatment of thymic disorders and myasthenia gravis. It has been shown that VATS is typically associated with reduced blood loss, shorter operative time, less trauma to the chest wall, shorter hospital stay, faster healing, and earlier return to normal activities. Video-assisted thoracoscopic surgery may also reduce the rate of postoperative complications by reducing tissue damage, postoperative pain, and the risk of infection $[15,16]$. Rapid healing time may also permit earlier administration of adjuvant chemo-radiation treatment in advanced cases [16-19].

There are some studies reporting the advantages in surgical outcomes of VATS for thymectomy. According to these reports, VATS thymectomy demonstrated a superior outcome in terms of hospital stay, intraoperative blood loss, and cosmetic satisfaction when compared with open access surgery [16, 20].

Video-assisted thoracoscopic surgery has some technical difficulties, so an increased rate of complications has been a major concern for VATS thymectomy. Despite this, recent reports on VATS thymectomy did not reveal any major complications $[18,21]$. Similarly, in our series, the postoperative complica- tion rate in the VATS group was not higher than that in the open surgery group (5.8\% vs. $8.6 \% ; p=0.381)$. Compared with VATS, open access surgery has been associated with increased postoperative complications including more frequent pain and pulmonary damage.

In our study, there was no difference in morbidity between the two groups, and also there was no difference in the incidence of wound infection, sternal infection, and respiratory complications. The average pain level using the visual analog pain score (VAS) was 4.3 for the VATS group and 3.5 for the open access group, and the difference was not significant $(p=0.118)$.

A serious complication associated with thymectomy in patients with myasthenia gravis is the myasthenic crisis. Meyer et al. [18] reported that postoperative mechanical ventilation was required in $4.3 \%$ of patients with thymoma who underwent VATS thymectomy. In our series, none of the patients experienced a myasthenic crisis. Only 1 (2.5\%) patient required $12 \mathrm{~h}$ of mechanical ventilation postoperatively.

There are some studies in the literature reporting serious complications including vascular injury, chylothorax, phrenic nerve damage, long-term air leakage and diaphragm injury with VATS thymectomy process. The overall morbidity was about 5.1-10\% [22-24].

In our study, conversion to thoracotomy was required in 1 patient in the VATS group due to bleeding from the right internal mammary artery; therefore, the conversion rate was $2.5 \%$ in all patients, while the figure was $5.8 \%$ for VATS thymectomy. Shorter postoperative length of hospital, less postoperative drainage and shorter duration of chest tube drainage have been reported with VATS thymectomy in the literature $[23,25,26]$. Our results were similar. Although longer operation times and more periop- 
erative blood loss were reported in the literature [8], our perioperative data showed that the difference between the two groups regarding operative time and perioperative blood loss was not statistically significant. One case, which was converted to thoracotomy due to bleeding from the right internal mammary artery, might be responsible for increased blood loss in the VATS group.

Tumor size is a major concern before considering VATS thymectomy. Girard et al. [27] stated that VATS was contraindicated for large tumors, whereas Youssef et al. [28] suggested that VATS thymectomy was appropriate for tumors smaller than $3 \mathrm{~cm}$ in diameter. In our study, tumor size was $5.17 \pm 3.2 \mathrm{~cm}$ in the thymoma group (VATS $2.5 \pm 2.4 \mathrm{~cm}$ vs. open access $4.7 \pm 3.7 \mathrm{~cm})$.

There are numerous studies confirming that VATS thymectomy results in less post-operative pain compared with open procedures [29, 30]. In contrast to these data, in our study the average pain level using the VAS was 4.3 for the VATS group and 3.5 for the open access group, and the difference was not significant $(p=0.118)$.

There were some limitations to this study. First of all, this was a single-institution experience with a relatively small sample size. Another limitation was the length of the follow-up period. In fact, patients with thymoma tend to have longer survival periods. No patient died of thymoma during the course of this study, although the length of follow-up was $33.3 \pm 26.3$ months, which was quite short. An additional limitation was the retrospective nature of data collection. A larger randomized series with a longer follow-up period is necessary in order to evaluate the oncological results.

\section{Conclusions}

We believe that VATS thymectomy can be performed for both neoplastic and non-neoplastic thymic diseases with minimal morbidity and mortality. Our data suggest that VATS thymectomy has some advantages over open surgery, including shorter length of hospital stay, less postoperative drainage and shorter duration of chest tube drainage. However, prospective randomized controlled trials with a longer follow-up time are warranted.

\section{Conflict of interest}

The authors declare no conflict of interest.

\section{References}

1. Agatsuma H, Yoshida K, Yoshino I, et al. Video-assisted thoracic surgery thymectomy versus sternotomy thymectomy in patients with thymoma. Ann Thorac Surg 2017; 104: 1047-53.

2. Landreneau RJ, Dowling RD, Castillo WM, et al. Thoracoscopic resection of an anterior mediastinal tumor. Ann Thorac Surg 1992; 54: 142-4.

3. Sabbagh MN, Garza JS, Patten B. Thoracoscopic thymectomy in patients with myasthenia gravis. Muscle Nerve 1995; 18: 1475-7.

4. Venuta F, Rendina EA, Anile M, et al. Thymoma and thymic carcinoma. Gen Thorac Cardiovasc Surg 2012; 60: 1-12.

5. Masaoka A, Monden Y, Nakahara K, et al. Follow-up study of thymomas with special reference to their clinical stages. Cancer 1981; 48: 2485-92.

6. Kondo K, Monden Y. Therapy for thymic epithelial tumors: a clinical study of 1,320 patients from Japan. Ann Thorac Surg 2003; 76: 878-84.

7. Yang Y, Dong J, Huang Y. Thoracoscopic thymectomy versus open thymectomy for the treatment of thymoma: a meta-analysis. Eur J Surg Oncol 2016; 42: 1720-8.

8. Siwachat S, Tantraworasin A, Lapisatepun W, et al. Comparative clinical outcomes after thymectomy for myasthenia gravis: thoracoscopic versus trans-sternal approach. Asian J Surg 2018; 41: 77-85.

9. Verschuuren JJ, Huijbers MG, Plomp JJ, et al. Pathophysiology of myasthenia gravis with antibodies to the acetylcholine receptor, muscle-specific kinase and low-density lipoprotein receptor-related protein 4. Autoimmun Rev 2013; 12: 918-23.

10. Gilhus NE, Skeie GO, Romi F, et al. Myasthenia gravis-autoantibody characteristics and their implications for therapy. Nat Rev Neurol 2016; 12: 259-68.

11. Raza A, Woo E. Video-assisted thoracoscopic surgery versus sternotomy in thymectomy for thymoma and myasthenia gravis. Ann Cardiothorac Surg 2016; 5: 33-7.

12. Kirchner T, Muller-Hermelink HK. New approaches to the diagnosis of thymic epithelial tumors. Prog Surg Pathol 1989; 10: 167-89.

13. Rosai J. Histological typing of tumours of the thymus. In: WHO International Histological Classification of Tumours. 2nd ed. Springer-Verlag, New York 1999; 5-15.

14. Osserman KE, Genkins G. Studies in myasthenia gravis: review of a twenty-year experience in over 1200 patients. Mt Sinai J Med 1971; 38: 497-537.

15. Lin MW, Chang YL, Huang PM, et al. Thymectomy for non-thymomatous myasthenia gravis: a comparison of surgical methods and analysis of prognostic factors. Eur J Cardiothorac Surg 2010; 37: 7-12.

16. Zahid I, Sharif S, Routledge T, et al. Video-assisted thoracoscopic surgery or transsternal thymectomy in the treatment of myasthenia gravis? Interact Cardiovasc Thorac Surg 2011; 12: 40-6.

17. Wright GM, Barnett S, Clarke CP. Video-assisted thoracoscopic thymectomy for myasthenia gravis. Intern Med J 2002; 32: 367-71.

18. Meyer DM, Herbert MA, Sobhani NC, et al. Comparative clinical outcomes of thymectomy for myasthenia gravis performed by extended transsternal and minimally invasive approaches. Ann Thorac Surg 2009; 87: 385-90. 
19. Savcenko M, Wendt GK, Prince SL, et al. Video assisted thymectomy for myasthenia gravis: an update of a single institution experience. Eur J Cardiothorac Surg 2002; 22: 978-83.

20. Ashleigh Xie, Richard T, Kevin P, et al. Video-assisted thoracoscopic surgery versus open thymectomy for thymoma: systematic review. Ann Cardiothorac Surg 2015; 4: 495-508.

21. Jurado J, Javidfar J, Newmark A, et al. Minimally invasive thymectomy and open thymectomy: outcome analysis of 263 patients. Ann Thorac Surg 2012; 94: 974-81.

22. Nakagiri T, Inoue M, Shintani Y, et al. Improved procedures and comparative results for video-assisted thoracoscopic extended thymectomy for myasthenia gravis. Surg Endosc 2015; 29: 2859-65.

23. Yuan ZY, Cheng GY, Sun KL, et al. Comparative study of videoassisted thoracic surgery versus open thymectomy for thymoma in one single center. J Thorac Dis 2014; 6: 726-33.

24. Özkan B, Toker A. Catastrophes during video-assisted thoracoscopic thymus surgery for myasthenia gravis. Interact Cardiovasc Thorac Surg 2016; 23: 450-3.

25. Liu TJ, Lin MW, Hsieh MS, et al. Video-assisted thoracoscopic surgical thymectomy to treat early thymoma: a comparison with the conventional transsternal approach. Ann Surg Oncol 2014; 21: 322-8.

26. Pennathur A, Qureshi I, Schuchert MJ, et al. Comparison of surgical techniques for early-stage thymoma: feasibility of minimally invasive thymectomy and comparison with open resection. J Thorac Cardiovasc Surg 2011; 141: 694-701.

27. Girard N, Mornex F, Van Houtte P, et al. Thymoma: a focus on current therapeutic management. J Thorac Oncol 2009; 4: 119-26.

28. Youssef SJ, Louie BE, Farivar AS, et al. Comparison of open and minimally invasive thymectomies at a single institution. Am J Surg 2010; 199: 589-93.

29. Ng CS, Wan IY, Yim AP. Video-assisted thoracic surgery thymectomy: the better approach. Ann Thorac Surg 2010; 89: 2135-41.

30. Cheng YJ, Kao EL, Chou SH. Videothoracoscopic resection of stage II thymoma: prospective comparison of the results between thoracoscopy and open methods. Chest 2005; 128: 3010-12.

Received: 28.01 .2018 , accepted: 4.03.2018 